\title{
Increasing Acetylcholine Levels in the Hippocampus or Entorhinal Cortex Reverses the Impairing Effects of Septal GABA Receptor Activation on Spontaneous Alternation
}

\author{
Aldemar Degroot ${ }^{1}$ and Marise B. Parent ${ }^{1,2,3,4}$ \\ ${ }^{1}$ Division of Neuroscience, ${ }^{2}$ Department of Psychology, and ${ }^{3}$ Department of Psychiatry, University of Alberta, \\ Edmonton, Alberta T6G 2E9 Canada
}

\begin{abstract}
Intra-septal infusions of the $\gamma$-aminobutyric acid (GABA) agonist muscimol impair learning and memory in a variety of tasks. This experiment determined whether hippocampal or entorhinal infusions of the acetylcholinesterase inhibitor physostigmine would reverse such impairing effects on spontaneous alternation performance, a measure of spatial working memory. Male Sprague-Dawley rats were given intra-septal infusions of vehicle or muscimol $(1 \mathrm{nmole} / 0.5 \mu \mathrm{L})$ combined with unilateral intra-hippocampal or intraentorhinal infusions of vehicle or physostigmine $(10 \mu \mathrm{g} / \mu \mathrm{L}$ for the hippocampus; $7.5 \mu \mathrm{g} / \mu \mathrm{L}$ or $1.875 \mu \mathrm{g} / 0.25$ $\mu \mathrm{L}$ for the entorhinal cortex). Fifteen minutes later, spontaneous alternation performance was assessed. The results indicated that intra-septal infusions of muscimol significantly decreased percentage-of-alternation scores, whereas intra-hippocampal or intra-entorhinal infusions of physostigmine had no effect. More importantly, intra-hippocampal or intra-entorhinal infusions of physostigmine, at doses that did not influence performance when administered alone, completely reversed the impairing effects of the muscimol infusions. These findings indicate that increasing cholinergic levels in the hippocampus or entorhinal cortex is sufficient to reverse the impairing effects of septal GABA receptor activation and support the hypothesis that the impairing effects of septal GABAergic activity involve cholinergic processes in the hippocampus and the entorhinal cortex.
\end{abstract}

Extensive evidence has implicated the medial septum in learning and memory. Lesions of the medial septum impair acquisition and retention performance in a variety of behavioral paradigms (Mitchell et al. 1982; Bolhuis et al. 1988; Fibiger et al. 1991; M'Harzi and Jarrard 1992). Furthermore, memory can be enhanced or impaired by intra-septal infusions of drugs that act at a variety of neurotransmitter systems (Brioni et al. 1990; Givens and Olton 1990; Markowska et al. 1990). For example, intra-septal infusions of $\gamma$-aminobutyric acid (GABA)ergic agonists impair memory during numerous tasks, including radial arm maze performance, inhibitory avoidance, water maze performance, spontaneous alternation, rewarded alternation, and visual discrimination (Brioni et al. 1990; Givens and Olton 1990; Chrobak and Napier 1992; Nagahara and McGaugh 1992; Nagahara et al. 1992; Parent and Gold 1997; Parent et al. 1997; Pang and Nocera 1998).

The septum contains cholinergic and GABAergic cell

${ }^{4}$ Corresponding author.

Current address: Department of Psychology, Georgia State University, University Plaza, Atlanta, GA 30303-3083.

E-MAIL psymbp@langate.gsu.edu; FAX (404) 651-3929.

Article and publication are at www.learnmem.org/cgi/doi/ $10.1101 / \mathrm{lm} .32200$. bodies that project to the hippocampus via the fimbriafornix (Wainer et al. 1985; Freund and Antal 1988; Kiss et al. 1990; Naumann et al. 1992). Extensive evidence indicates that the septo-hippocampal system is involved in memory processes (Galey et al. 1989; Marighetto et al. 1989; Ammassari-Teule and Maho 1992; Dalrymple-Alford 1994; Izquierdo and Medina 1995). For instance, lesions of the fimbria-fornix produce robust memory deficits (Nilsson et al. 1987; Aggleton et al. 1992; Dickinson-Anson et al. 1998). Furthermore, lesions of the medial septum or the fimbriafornix eliminate hippocampal theta rhythm, an effect that is associated with memory deficits (Bland 1986; Dutar et al. 1995; Givens 1995).

More specifically, the role of the medial septum in learning and memory appears to involve an influence on cholinergic processes in the hippocampus (Brioni et al. 1990; Durkin 1992). Lesions of the septo-hippocampal pathway decrease acetylcholinesterase (AChE) staining intensity (Erb et al. 1997) and extracellular acetylcholine (ACh) levels in the hippocampus (Nilsson et al. 1990). In some instances, IgG saporin-induced lesions of the cholinergic septo-hippocampal projection impair spatial working memory (BergerSweeney et al. 1994; Dornan et al. 1996; Walsh et al. 1996; also see Baxter et al. 1995; Bannon et al. 1996; Pang and

LEARNING \& MEMORY 7:293-302 @ 2000 by Cold Spring Harbor Laboratory Press ISSN1072-0502/00 \$5.00

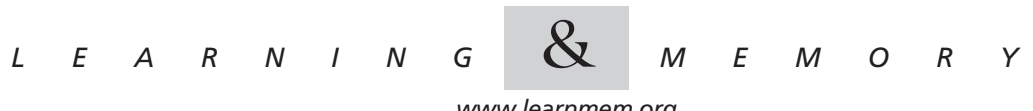


Nocera 1998). Furthermore, hippocampal grafts of ACh-producing cells attenuate the memory-impairing effects of fimbria-fornix lesions (Dunnett et al. 1982; Nilsson and Björklund 1992; Dickinson-Anson et al. 1998).

Like the effects of septal lesions, the memory-modulating effects of intra-septal drug infusions also appear to involve cholinergic processes in the hippocampus. Intra-septal infusions of the cholinergic antagonist scopolamine, at doses that impair learning and memory, also decrease extracellular cholinergic levels in the hippocampus (Gorman et al. 1994). Administration of benzodiazepines into the medial septum decreases hippocampal ACh levels (Imperato et al. 1993, 1994) and impairs learning and memory (McNamara and Skelton 1995; Stackman and Walsh 1995). Similarly, intra-septal infusions of muscimol prevent traininginduced increases in hippocampal ACh (Durkin 1992; Moor et al. 1998) and reduce high-affinity choline uptake (HACU), ACh turnover rate, and extracellular ACh levels in the hippocampus (Costa et al. 1983; Wood 1986; Durkin 1992; Walsh et al. 1993; Gorman et al. 1994; Moor et al. 1998). The effects of intra-septal infusions of muscimol on hippocampal ACh indices are correlated with the effects of muscimol on memory (Brioni et al. 1990; Durkin 1992). For example, only those doses of muscimol that impair memory in the water maze task decrease HACU in the hippocampus (Brioni et al. 1990).

We previously showed that the impairing effects of intra-septal infusions of muscimol are reversed by simultaneous infusions of glucose into the hippocampus (Parent et al. 1997). Intra-hippocampal infusions of glucose may overcome the muscimol-induced deficit by upregulating cholinergic levels in the hippocampus. Glucose is linked to the synthesis of ACh (Gibson and Blass 1976; Gibson et al. 1978). Furthermore, glucose elevates extracellular ACh levels in the hippocampus of behaving rats (Ragozzino et al. 1996, 1998) and increases hippocampal HACU when the hippocampal cholinergic system is pharmacologically challenged (Micheau et al. 1995). In addition, increases in glucose attenuate memory impairments induced by cholinergic antagonists (Stone et al. 1988).

The evidence indicating that septal GABAergic receptors influence memory via an influence on the hippocampal cholinergic system is extensive but primarily indirect. That is, the effects of intra-septal infusions of muscimol on hippocampal cholinergic measures and memory have been examined in different groups of animals or in the same animal on separate occasions. Consequently, experiment 1 examined the effects of simultaneously manipulating septal GABAergic receptors and the hippocampal cholinergic system in a rat performing a learning and memory task. Specifically, the goal of experiment 1 was to determine whether intra-hippocampal infusions of the AChE inhibitor physostigmine would reverse the impairing effects of intra- septal infusions of the GABA agonist muscimol on spontaneous alternation.

In addition to sending the projection to the hippocampus, the septum sends a cholinergic projection to the entorhinal cortex (Srebro et al. 1979; Wyss et al. 1979; Alonso and Köhler 1984; Jones 1993). Limited evidence suggests that the septo-entorhinal projection may also be involved in learning and memory. For example, Walsh et al. (1996) found that lesions of septal cholinergic projection neurons, which included damage to the cholinergic projection to the entorhinal cortex, impair radial arm maze performance. These results suggest that the medial septum may influence memory via a process that also involves an effect on the ACh system in the entorhinal cortex. As a result, experiments 2 and 3 determined whether infusions of physostigmine into the entorhinal cortex would reverse deficits in spontaneous alternation produced by intra-septal infusions of muscimol.

\section{RESULTS AND DISCUSSION}

\section{Experiment 1}

Figure 1A,B shows the location of the infusion sites in the medial septum and dorsal hippocampus, respectively, of the rats whose data were included in the statistical analysis. Eleven rats were given infusions of vehicle in both the hippocampus and medial septum (VEH-VEH), eight rats were given infusions of physostigmine in the hippocampus and vehicle in the medial septum (PHYSO-VEH), 10 rats were given infusions of vehicle in the hippocampus and muscimol in the medial septum (VEH-MUSC), and 11 rats were given infusions of physostigmine in the hippocampus and muscimol in the medial septum (PHYSO-MUSC).

The behavioral results indicated that the infusions into the hippocampus and septum significantly affected spontaneous alternation performance $(\mathrm{F}[3,36]=7.94 ; P<0.001$; see Fig. 2A). As expected, intra-septal infusions of muscimol impaired spontaneous alternation performance. The percentage-of-alternation scores of VEH-MUSC rats were significantly lower than those of VEH-VEH rats $(P<0.5)$. Infusions of physostigmine into the hippocampus did not affect spontaneous alternation performance. The percentage-of-alternation scores of PHYSO-VEH rats were not significantly different from those of VEH-VEH rats $(P>0.05)$. Importantly, infusions of physostigmine into the hippocampus reversed the impairing effects of the intra-septal infusions of muscimol. The percentage-of-alternation scores of PHYSO-MUSC rats were significantly higher than those of VEH-MUSC rats $(P<0.05)$ but were not different from those of VEH-VEH rats $(P>0.05)$.

The infusions also affected the number of arms the rats entered in the maze $(\mathrm{F}[3,36]=4.8 ; P<0.01$; see Fig. $2 \mathrm{~B})$. Specifically, PHYSO-MUSC rats entered less arms than did VEH-VEH rats $(P<0.05)$. However, the performance of

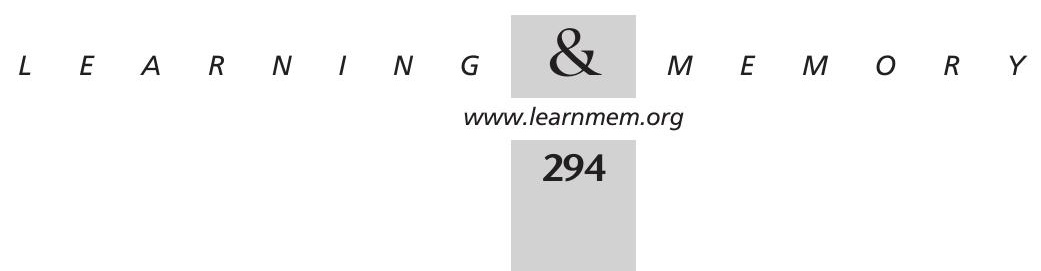


A

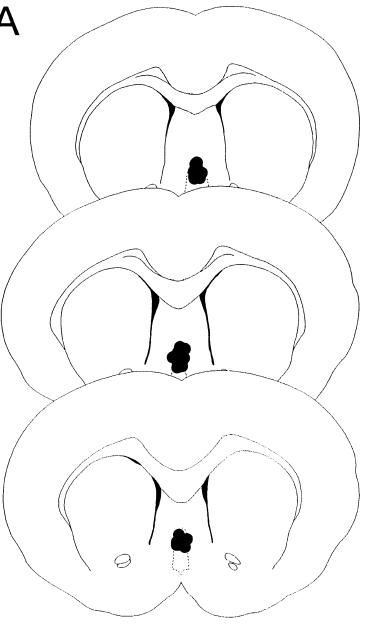

B

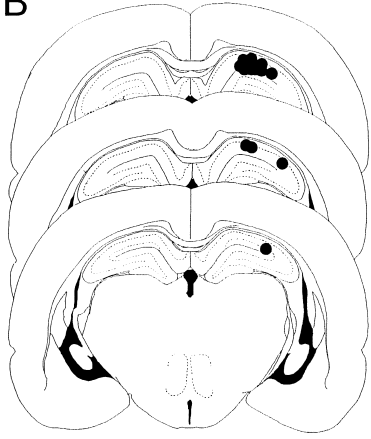

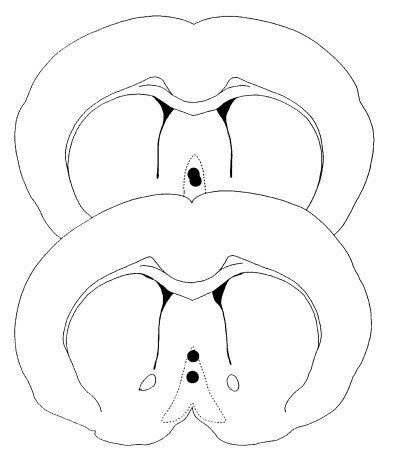

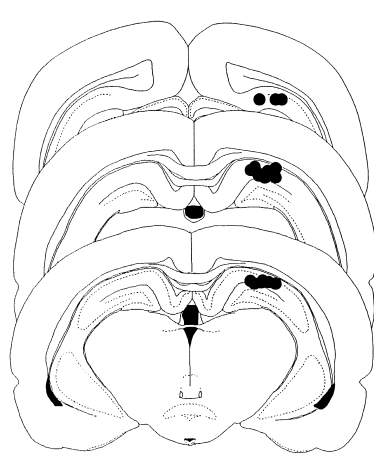

Figure 1 Schematic illustration of a coronal section of the rat brain showing the approximate location of medial septal $(A)$ and hippocampal $(B)$ infusion sites in experiment 1. Atlas plates adapted from Paxinos and Watson (1986).

PHYSO-VEH and VEH-MUSC rats did not significantly differ from that of VEH-VEH rats $(P>0.05)$.

The effects of the infusions on the number of arms the rats entered did not mirror the effects of the infusions on spontaneous alternation. There was no significant correlation between spontaneous alternation performance and the number of arms the rats entered in the maze $(r[38]=0.09$; $P>0.05)$.

The present results demonstrate that infusions of the AChE inhibitor physostigmine into the dorsal hippocampus reverse the impairing effect of muscimol infusions into the medial septum on spontaneous alternation performance. These findings support the hypothesis that the impairing effects of intra-septal infusions of muscimol involve cholinergic processes in the hippocampus. The effects of the drugs on spontaneous alternation were not likely related to changes in locomotor activity, because the effects of the drugs on the number of arms the rats entered in the maze and the percentage-of-alternation scores were not significantly correlated. For example, muscimol impaired alternation performance without affecting the number of arms the

rats entered in the maze. The simultaneous infusion of physostigmine and muscimol did significantly decrease the number of arms the rats entered in the maze. However, this finding does not likely account for the ability of physostigmine to reverse the muscimol-induced deficit. A decrease in arm entries would likely lengthen the latency among arm choices and increase the mnemonic demands of the task (Dember 1989).

\section{Experiment 2}

Figure 3 shows the location of the infusion sites in the entorhinal cortex of the rats whose data were included in the statistical analyses. The septal placements were comparable to those shown in Figure 1. Seven rats were given infusions of vehicle in both the entorhinal cortex and the medial septum (VEH-VEH), five rats were given infusions of physostigmine in the entorhinal cortex and vehicle in the medial septum (PHYSO-VEH), six rats were given infusions of vehicle in the entorhinal cortex and muscimol in the

\section{A}

B
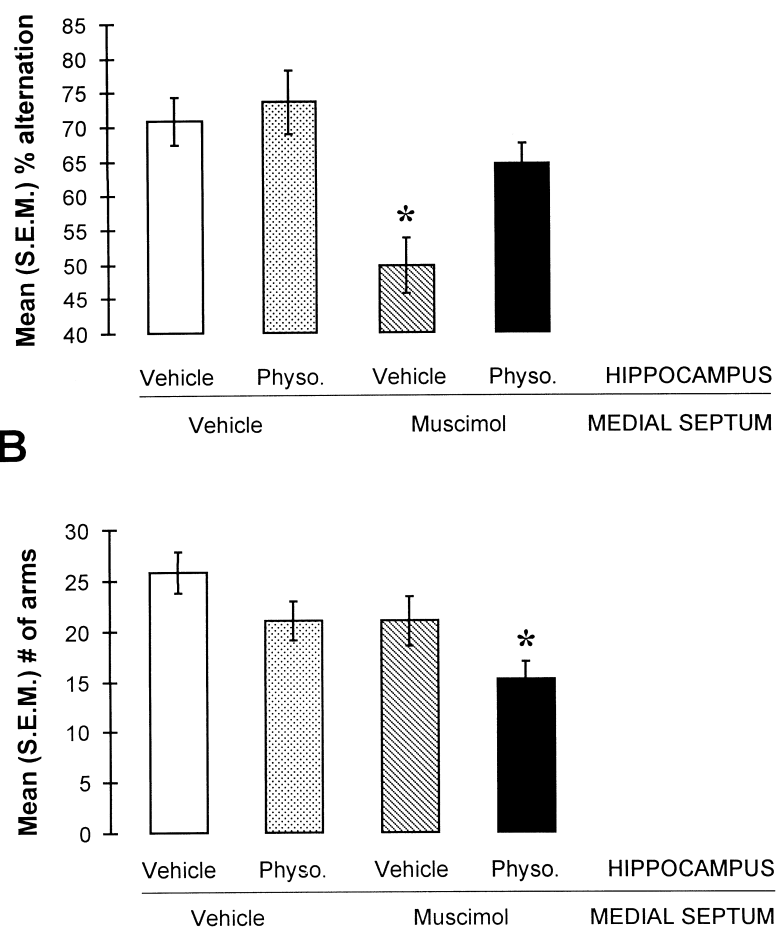

Figure 2 (A) Infusions of physostigmine $(10 \mu \mathrm{g} / 1 \mu \mathrm{L})$ into the dorsal hippocampus reverse the impairing effects of intra-septal infusions of muscimol $(114 \mathrm{ng} / 0.5 \mu \mathrm{L})$ on spontaneous alternation performance $(* P<0.05$ vs. all other groups). (B) The effects of the infusions on the number of arms the rats entered in the maze did not parallel the effects of the infusions on the percentage-of-alternation scores. Concurrent infusions of physostigmine into the hippocampus and muscimol in the medial septum significantly reduced the number of arms the rats entered in the maze $(* P<0.05$ vs. VEH-VEH).

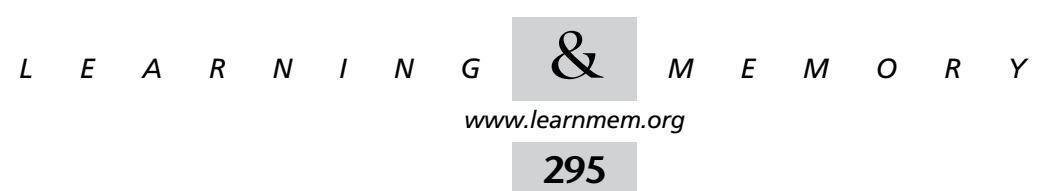


medial septum (VEH-MUSC), and six rats were given infusions of physostigmine in the entorhinal cortex and muscimol in the medial septum (PHYSO-MUSC).

The medial septal and entorhinal cortex infusions significantly affected spontaneous alternation performance $(\mathrm{F}[3,20)=5.23 ; P<0.01$; see Fig. $4 \mathrm{~A})$. As in experiment 1 , the infusions of muscimol into the septum significantly impaired spontaneous alternation performance. The percentage-of-alternation scores of VEH-MUSC rats were significantly lower than those of VEH-VEH rats $(P<0.05)$. Infusions of physostigmine into the entorhinal cortex did not affect spontaneous alternation performance. The percentage-of-alternation scores of PHYSO-VEH rats were not significantly different from those of VEH-VEH rats $(P>0.05)$. However, infusions of physostigmine into the entorhinal cortex reversed the impairing effects of intra-septal infusions of muscimol. The percentage-of-alternation scores of PHYSO-MUSC rats were significantly higher than those of VEH-MUSC rats $(P<0.05)$ but were not different from those of VEH-VEH rats $(P>0.05)$.

Figure $4 \mathrm{~B}$ illustrates that the infusions did not affect the number of arms the rats entered in the maze $(\mathrm{F}[3,20]=$ $0.13 ; P>0.05)$.

The findings of experiment 2 demonstrate that like the effects of infusions of physostigmine into the hippocampus, infusions of physostigmine into the entorhinal cortex reverse the impairing effects of intra-septal infusions of muscimol on spontaneous alternation performance. These findings raise the possibility that the impairing effects of medial septal GABA receptor activation may also involve the cholinergic system in the entorhinal cortex. The effects of muscimol and physostigmine do not appear to be related to changes in locomotor activity, because the infusions did not significantly affect the number of arms the rats entered in the maze.

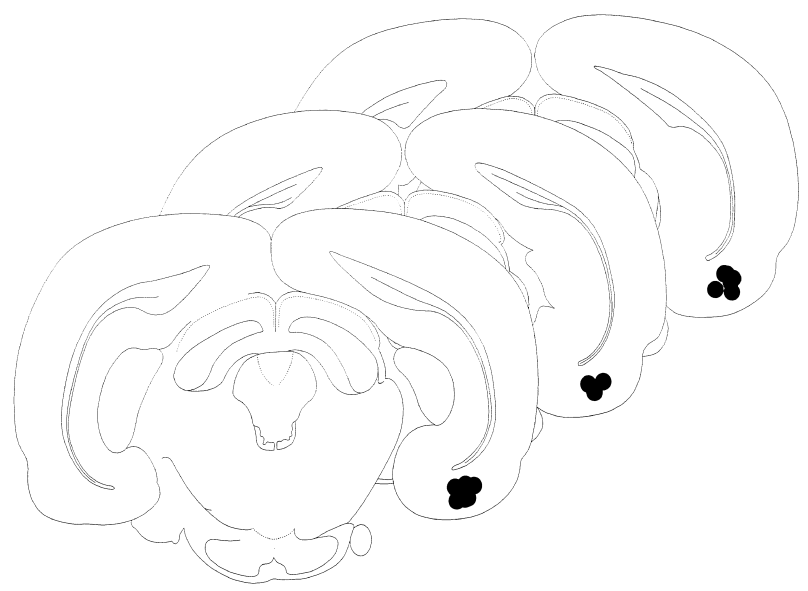

Figure 3 Schematic illustration of a coronal section of the rat brain showing the approximate location of entorhinal cortex infusion sites in experiment 2. Atlas plates adapted from Paxinos and Watson (1986).
A
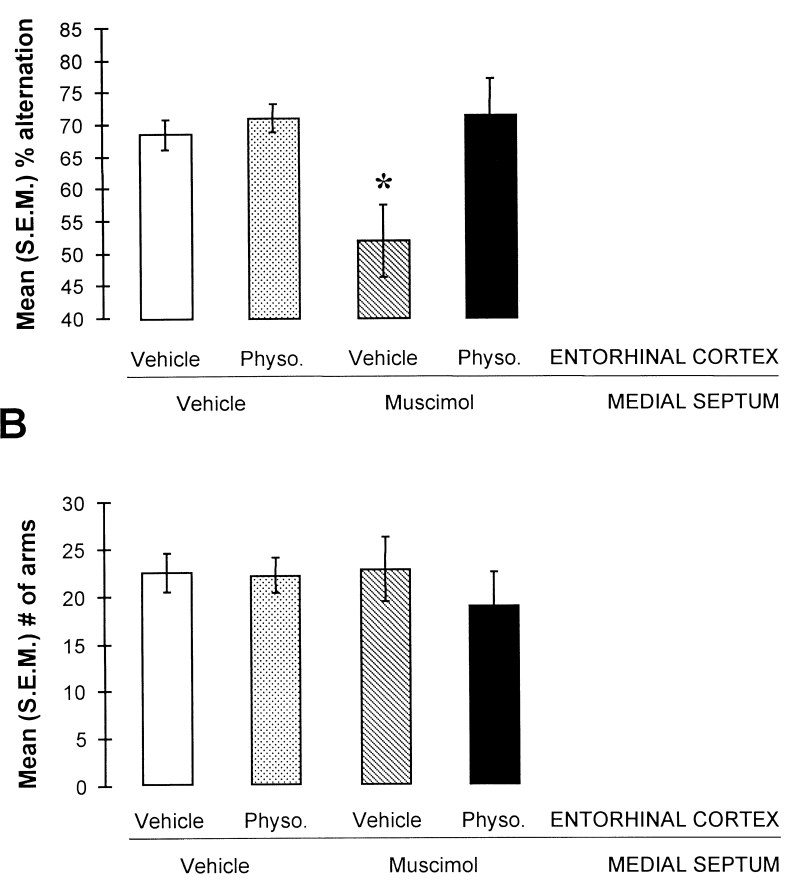

Figure $4 \quad(A)$ Infusions of physostigmine $(7.5 \mu \mathrm{g} / 1 \mu \mathrm{L})$ into the entorhinal cortex reverse the impairing effects of intra-septal infusions of muscimol on spontaneous alternation performance $\left({ }^{*} P<0.05\right.$ vs. all other groups). (B) The infusions do not affect the number of arms the rats entered in the maze $(P>0.05)$.

Although the findings of experiment 2 implicate cholinergic processes in the entorhinal cortex in spontaneous alternation, the possibility remains that the relatively large volume $(1 \mu \mathrm{L})$ of physostigmine influenced performance by diffusing to proximal structures. For example, physostigmine could have affected cholinergic processes in the ventral hippocampus, a neural region that also receives a cholinergic projection from the medial septum (Milner et al. 1983; Jakab and Leranth 1995). A relatively large volume was used initially to first determine if it was possible to obtain an effect of physostigmine in the entorhinal cortex. However, to more clearly implicate cholinergic processes in the entorhinal cortex, experiment 3 examined the effects of infusing a smaller volume $(0.25 \mu \mathrm{L})$ of the same concentration of physostigmine into the entorhinal cortex.

\section{Experiment 3}

The results of the histological analysis indicated that placement of the cannulae in the septum and entorhinal cortex was comparable to the placements shown in Figures 1A and 3 , respectively (VEH-VEH, $n=7$; PHYSO-VEH, $n=8$; VEHMUSC, $n=10$; PHYSO-MUSC, $n=8$ ).

As in experiment 2, the medial septal and entorhinal cortex infusions significantly affected spontaneous alterna-

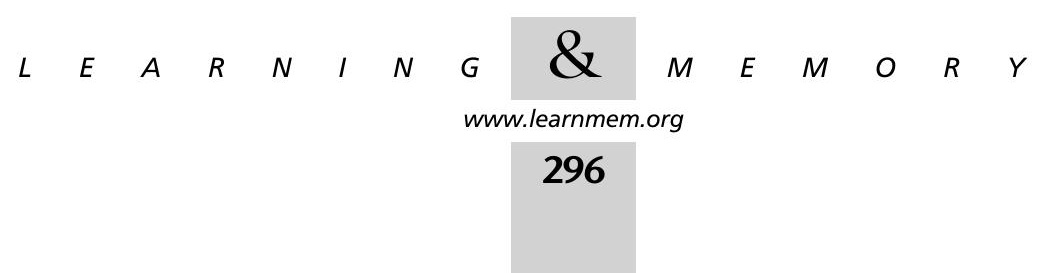


A
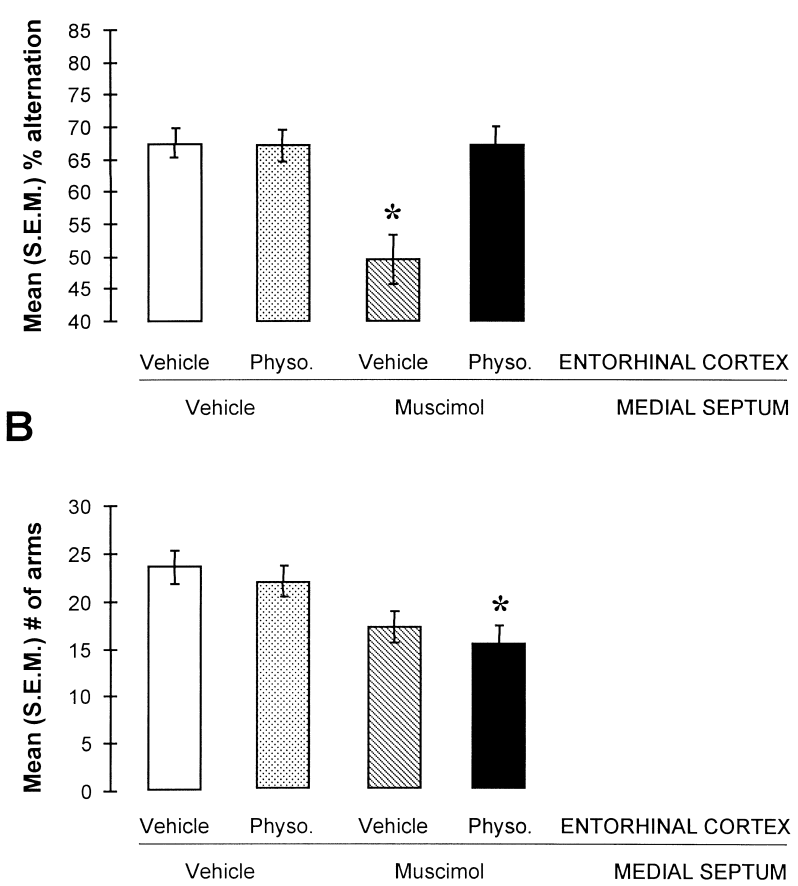

Figure 5 (A) Infusions of physostigmine $(1.875 \mu \mathrm{g} / 0.25 \mu \mathrm{L})$ into the entorhinal cortex in a volume smaller than that used in experiment 2 also reverse the impairing effects of intra-septal infusions of muscimol on spontaneous alternation performance ${ }^{*} P<0.05$ vs. all other groups). (B) The effects of the infusions on the number of arms the rats entered in the maze do not parallel the effects of the infusions on the percentage-of-alternation scores. Concurrent infusions of physostigmine into the entorhinal cortex and muscimol into the medial septum significantly reduce the number of arms the rats enter in the maze $(* P<0.05$ vs. VEH-VEH).

tion performance $(\mathrm{F}[3,29]=9.09 ; P<0.001$; see Fig. $5 \mathrm{~A})$. Infusions of muscimol into the septum significantly impaired spontaneous alternation performance. The percentage-of-alternation scores of VEH-MUSC rats were significantly lower than those of VEH-VEH rats $(P<0.05)$. Infusions of physostigmine into the entorhinal cortex did not affect spontaneous alternation performance. The percentage-of-alternation scores of PHYSO-VEH rats were not significantly different from those of VEH-VEH rats $(P>0.05)$. Like the effects of the larger volume $(1 \mu \mathrm{L})$ of physostigmine used in experiment 2 , the results of experiment 3 indicated that infusions of a smaller volume $(0.25 \mu \mathrm{L})$ of physostigmine into the entorhinal cortex reversed the impairing effects of the intra-septal infusions of muscimol. The percentage-of-alternation scores of PHYSO-MUSC rats were significantly higher than those of VEH-MUSC rats $(P<0.05)$ but were not different from those of VEH-VEH rats $(P>0.05)$.

Figure $5 \mathrm{~B}$ indicates that the infusions also affected the number of arms the rats entered in the maze $(\mathrm{F}[3,29]=4.77 ; P<0.01)$. Specifically, PHYSO-MUSC rats entered less arms than did VEH-VEH rats $(P<0.05)$. How- ever, PHYSO-VEH and VEH-MUSC rats did not significantly differ from VEH-VEH rats $(P>0.05)$.

The effects of the infusions on the number of arms entered were not paralleled by the effects of the infusions on spontaneous alternation. There was no significant correlation between spontaneous alternation performance and the number of arms the rats entered in the maze $(r[31]=0.19 ; P>0.05)$.

The findings of experiment 3 demonstrate that like the effects of a $1-\mu \mathrm{L}$ infusion, infusions of a smaller volume of physostigmine $(0.25 \mu \mathrm{L})$ into the entorhinal cortex also block the impairing effects of intra-septal infusions of muscimol on spontaneous alternation performance. These findings suggest that medial septal GABAergic receptors may impair memory via a process that involves the cholinergic system in the entorhinal cortex. The effects of the infusions on spontaneous alternation do not appear to be related to changes in locomotor activity, because the effects of the infusions on percentage-of-alternation scores and the number of arms the rats entered in the maze were not significantly correlated.

\section{General Discussion}

The present results indicate that upregulating cholinergic levels in the hippocampus or the entorhinal cortex completely reverses spontaneous alternation deficits produced by stimulating medial septal GABAergic receptors. Specifically, the findings of experiment 1 indicate that intra-hippocampal infusions of the AChE inhibitor physostigmine fully reverse the impairing effects of intra-septal infusions of muscimol. Furthermore, the results indicate that this effect does not appear to be associated with drug-induced differences in locomotor activity. Likewise, the results of experiments 2 and 3 demonstrate that infusions of physostigmine into the entorhinal cortex can also reverse the memoryimpairing effects of intra-septal infusions of muscimol.

In the present experiments, we simultaneously manipulated both the septal GABAergic and hippocampal cholinergic neurotransmitter systems while a rat was exploring a maze. Consequently, in comparison with previous findings, our results provide more direct evidence to support the hypothesis that stimulating GABAergic receptors in the medial septum impairs learning and memory through a process that involves a decrease in cholinergic levels in the hippocampus (Chrobak et al. 1989; Brioni et al. 1990; Givens and Olton 1990; Durkin 1992; Walsh et al. 1993; Gorman et al. 1994; Moor et al. 1998). The results obtained in experiment 1 are analogous to those obtained by Parent et al. (1997), who found that intra-hippocampal infusions of glucose reversed the impairing effects of intra-septal infusions of muscimol. Intra-hippocampal glucose perfusions increase hippocampal cholinergic levels when the cholinergic system is challenged (Ragozzino et al. 1998). Combined with the present results, these latter findings suggest

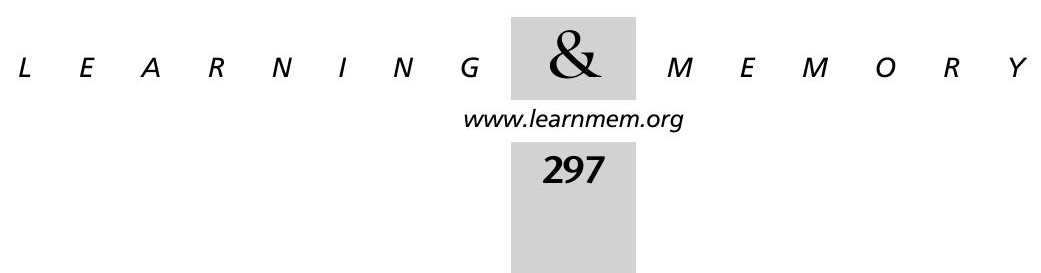


that intra-hippocampal infusions of glucose may have reversed the muscimol-induced deficit by increasing hippocampal ACh levels.

In the present study, we chose to examine the effects of unilateral infusions into the hippocampus and entorhinal cortex for a number of reasons. First, we reasoned that unilateral infusions might be sufficient to overcome the deficits produced by intra-septal infusions of muscimol because we and others have shown previously that unilateral manipulations of the hippocampus affect learning and memory and neurochemical indices (Packard et al. 1994, 1996; Cooper and Sofroniew 1996; Parent et al. 1997; Kimonides et al. 1998; Packard and Teather 1998; Ragozzino et al. 1998; Roozendaal et al. 1999). Second, there are extensive connections among the two hippocampi and the two entorhinal cortices (Amaral et al. 1984; Demeter et al. 1985; Christesen and Sorensen 1989; Fernandes de Lima et al. 1990; Gloor et al. 1993). It is possible that infusing physostigmine in one hemisphere affects the hippocampus or entorhinal cortex bilaterally. The recent demonstration by Ragozzino et al. (1998) that perfusing glucose into the hippocampus of one hemisphere increases ACh levels in the hippocampus of both hemispheres supports this possibility. Another rationale for the unilateral design is that only two cannulae need to be accurately implanted rather than three. Consequently, fewer rats are needed to perform these experiments. We reasoned that if the unilateral manipulations did not interact with the effects of muscimol, we would then proceed to an examination of the effects of bilateral manipulations. However, as our results indicate, the unilateral infusions were effective.

Although our findings indicate that increasing cholinergic levels in the hippocampus are sufficient to overcome deficits produced by septal GABA receptor activation, it is not clear which septal projection neurons participate in these effects. GABAergic receptors are present on both cholinergic and GABAergic septo-hippocampal projection neurons (Van der Zee and Luiten 1994; Gao et al. 1995; Henderson 1995; Levey et al. 1995). One way that muscimol may impair memory is by inhibiting the cholinergic projection neurons. According to this hypothesis, physostigmine reverses the muscimol-induced deficit by increasing ACh levels at these cholinergic terminals. However, the finding that lower doses of muscimol are sufficient to impair spatial working memory when the cholinergic projection is lesioned (Pang and Nocera 1998) suggests that the septohippocampal GABAergic projection is also involved in the effects of muscimol on memory. Unfortunately, there is limited evidence regarding the role of the septo-hippocampal GABA projection in memory. Recent findings indicate that septal infusions of cholinergic agonists, which are known to enhance memory (Givens and Olton 1994; Markowska et al. 1995), excite septo-hippocampal GABAergic but not cholinergic projection neurons (Wu et al. 2000). As septo-hip- pocampal GABAergic neurons synapse onto GABAergic interneurons, cholinergic agonist-induced stimulation of the septo-hippocampal GABA projection dis-inhibits hippocampal pyramidal cells (Toth et al. 1997). Thus, another way that muscimol may impair memory is by inhibiting the GABAergic projection, which would be expected to decrease hippocampal pyramidal cell activity. Future experiments are needed to examine the interaction between muscimol and physostigmine in rats with selective lesions of the cholinergic (Pang and Nocera 1998) or GABAergic projection (Secor et al. 1999).

To our knowledge, our findings are the first to suggest that septal GABAergic receptors may also influence memory via an effect on cholinergic processes in the entorhinal cortex. Our findings are consistent with those of Walsh et al. (1996), who found that intra-septal infusions of the cholinergic toxin IgG saporin decreased cholinergic innervation of the entorhinal cortex (and hippocampus and cingulate cortex) and impaired memory in a variable-delay radial-arm maze task. We are confident that the effects of physostigmine resulted from a specific effect on synapses in the entorhinal cortex. First, we show that small volumes of physostigmine $(0.25 \mu \mathrm{L})$ are as effective as larger volumes $(1.0$ $\mu \mathrm{L})$. Second, an analysis of the data obtained from rats with misplaced cannulae (data not shown) indicates that the drug effect is specific to the entorhinal cortex. Although the sample size is small $(n=4)$, our results indicate that physostigmine ( $1 \mu \mathrm{L}, n=2 ; 0.25 \mu \mathrm{L}, n=2)$ did not reverse muscimol-induced deficits when the infusions were too dorsal.

The present findings do not indicate whether the entorhinal cortex mediates its effect on spontaneous alternation via its connection to the hippocampus or whether it acts independently of the hippocampus. The entorhinal cortex provides a major excitatory input to the hippocampus via the perforant path (Gauthier and Destrade 1984). There is evidence suggesting that the entorhinal cortex regulates memory by gating the entry of information into the hippocampus (Jarrard et al. 1984; Iijama et al. 1996). Alternately, other findings suggest that the entorhinal cortex may play a distinct role in memory processes that is independent of the hippocampus (Gauthier and Destrade 1984). Future experiments are needed to determine whether intra-entorhinal infusions of physostigmine reverse the impairing effects of septal GABA receptor activation when the perforant path is lesioned.

It is possible that muscimol ultimately impairs memory by downregulating glutamatergic levels in the hippocampus. Cholinergic neurons synapse onto glutamatergic cells in the hippocampus (Moor et al. 1996). The individual roles of glutamatergic and cholinergic processes in the hippocampus have been well demonstrated (Izquierdo et al. 1993; Staubli et al. 1994; Ohno and Watanabe 1996). Evidence suggests that the glutamatergic and cholinergic systems in the hippocampus interact during learning and

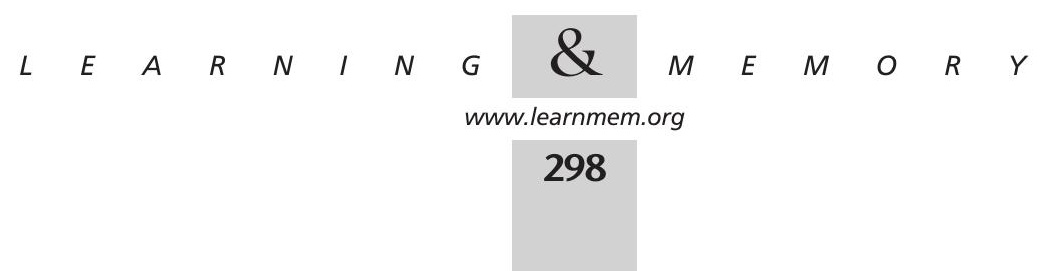


memory. Ineffective doses of a cholinergic antagonist and a glutamatergic antagonist significantly impair inhibitory avoidance (Ohno and Watanabe 1996) and visual recognition memory (Matsuoka and Aigner 1996) when the two are co-infused. Further, ACh amplifies $N$-methyl-D-aspartate receptor-mediated responses in a hippocampal slice (Markram and Segal 1990). These combined findings raise the possibility that the physostigmine-induced upregulation of cholinergic levels in the hippocampus might reverse the impairing effects of intra-septal infusions of muscimol by increasing glutamatergic levels. Future experiments need to examine whether intra-hippocampal infusions of glutamate will reverse the impairing effects of septal GABA receptor activation. In addition, experiments are also needed to determine whether increasing cholinergic levels in the ventral hippocampus would reverse deficits induced by intra-septal infusions of muscimol, because the medial septum also sends a cholinergic projection to this area (Milner et al. 1983; Jakab and Leranth 1995).

In summary, the present findings demonstrate that infusions of the AChE inhibitor physostigmine into the hippocampus or the entorhinal cortex completely reverse the impairing effects of intra-septal infusions of the GABA agonist muscimol on spontaneous alternation. These findings suggest that septal GABAergic receptors may impair memory by downregulating ACh levels in the hippocampus and the entorhinal cortex.

\section{MATERIALS AND METHODS}

\section{Experiment 1}

Male Sprague-Dawley rats, weighing 250-300 g upon arrival, were used. They were individually housed and maintained on a 12-hlight/12-h-dark cycle and given ample food and water. All rats were handled $2 \mathrm{~d}$ before surgery for $3 \mathrm{~min}$ each. During handling, the rats were given an oral administration of water to habituate them to the oral administration of an analgesic on the day of surgery.

Surgery was performed at least $1 \mathrm{wk}$ after the rats arrived. On the day of surgery, the rats were given an oral administration of the analgesic acetaminophen (Tylenol; $120 \mathrm{mg} / 1.5 \mathrm{cc}$ ). One hour later, they were given atropine sulfate $(0.2 \mathrm{cc}$ i.p.) to reduce respiratory complications produced by the anaesthetic. Subsequently, rats were anaesthetized with pentobarbital (Nembutal; $50 \mathrm{mg} / \mathrm{kg}$ i.p.), hydrated with saline ( 3 cc s.c.), and given the antibiotic penicillin (0.05 cc i.m.; Crystiben, Rhone Merieux Canada Inc.). Stereotaxic surgical procedures were used to implant one 22-gauge stainlesssteel guide cannula (Plastics One, Inc., Roanoke, VA) aimed at the medial septum $(0.5 \mathrm{~mm}$ anterior to bregma [AP], $4.9 \mathrm{~mm}$ ventral to dura $[D V]$, nose bar $=-3.2 \mathrm{~mm}$ from the interaural line; Paxinos and Watson 1986) and one guide cannula aimed at the dorsal hippocampus $(-4.2 \mathrm{~mm} \mathrm{AP}, 2.0 \mathrm{~mm} \mathrm{DV}, 4.1 \mathrm{~mm}$ lateral [ML] to the midline). For half the rats, the hippocampal cannula was implanted in the left hemisphere. The cannulae were attached to the skull with four jeweler's screws and cranioplastic cement. A dummy cannula was inserted into each guide cannula to keep the cannula tract clear. Immediately after surgery, the rats were placed into a warm environment until they regained consciousness. Two days after surgery, each cannula was checked for obstructions, and betadine was applied to the surgical wound.

All rats were handled for 3 min at $2 \mathrm{~d}$ before behavioral testing and for $5 \mathrm{~min}$ the day before testing. Testing occurred at least $1 \mathrm{wk}$ after surgery between 0900 and $1900 \mathrm{~h}$. Rats were given an infusion of vehicle (phosphate-buffered saline [PBS], $\mathrm{pH}$ 7.4) or physostigmine ( $10 \mu \mathrm{g} / \mu \mathrm{L}$ for $1 \mathrm{~min}$ ) into the hippocampal cannula, followed immediately by an infusion of PBS or muscimol (114 ng/ $0.5 \mu \mathrm{L}$ for $1 \mathrm{~min}$ ) into the medial septal cannula. The solutions were infused through a 28-gauge injection needle that extended $1 \mathrm{~mm}$ beyond the guide cannula. The needle was connected to a $10-\mu \mathrm{L}$ Hamilton syringe by polyethylene tubing, and the infusions were delivered using an infusion pump (Harvard Apparatus 22). The injection needles were left in place for $1 \mathrm{~min}$ after the infusions to allow for diffusion. The dose of physostigmine was selected on the basis of pilot experiments indicating that this was the highest dose that did not affect spontaneous alternation performance when infused alone into the dorsal hippocampus. The muscimol dose was selected on the basis of previous work (Chrobak et al. 1989; Brioni et al. 1990; Parent et al. 1997).

Evidence suggests that spontaneous alternation is a measure of spatial working memory. To alternate among spatial locations, a rat must remember its previous location. A spatial working memory component is supported by evidence that indicates that alternation scores are lowered by the removal of directional cues (Richman et al. 1987) or by increasing the temporal interval among location choices (Livesay et al. 1981; Hepler et al. 1985; Beninger et al. 1986; Shannon et al. 1990; Kelsey and Vargas 1993; Ragozzino et al. 1996). Furthermore, evidence suggests that the effects of septal manipulations on spontaneous alternation are similar to the effects of these manipulations on other measures of spatial working memory, such as rewarded alternation and alternation in the water maze and in the radial arm maze (Chrobak et al. 1989; Brioni et al. 1990; Givens and Olton 1990, 1994; Durkin 1992; Nagahara and McGaugh 1992; Nagahara et al. 1992; Markowska et al. 1995; Wan et al. 1995). Spontaneous alternation has the advantage over these tasks in that food deprivation or immersion in water is not required to motivate the rats.

Spontaneous alternation performance was assessed using a Y-maze composed of three equally spaced arms $\left(120^{\circ} ; 60 \mathrm{~cm}\right.$ long $\times 17.5 \mathrm{~cm}$ high). The floor of each arm consisted of stainless steel $(3.5 \mathrm{~cm}$ wide), and each arm was covered with a translucent Plexiglas lid. Each rat was placed in one arm of the maze and allowed to explore the three arms for $8 \mathrm{~min}$; the number and sequence of arms the rats entered were recorded. An alternation consisted of entering three different arms consecutively. For instance, each alternation is followed by a comma in the following sequence of arm entries (each arm is labeled A, B, or C): ACB,CA,B,C,A,CAB,C,A,. In this example, the rat entered 14 arms, eight of which were alternations. For each rat, a percentage-of-alternation score was computed by dividing the number of alternations the rat made by the number of arms entered minus two. The resulting number was multiplied by 100 . The behavioral results of rats that entered $<10$ arms were not included in the data analysis. Fifteen rats entered $<10$ arms in experiment 1 (VEH-MUSC, $n=7$; PHYSO-MUSC, $n=8$ ).

After completion of the behavioral tests, rats were killed with an overdose of chloral hydrate and perfused them intracardially with $0.9 \%$ saline followed by $10 \%$ formalin. The brains were removed and placed in a $10 \%$ formalin solution. At least $48 \mathrm{~h}$ later, the brains were frozen and sectioned $(60 \mu \mathrm{m})$, mounted onto glass slides, and stained with thionin. The cannula location for each rat was determined using a microscope by an observer blind to the

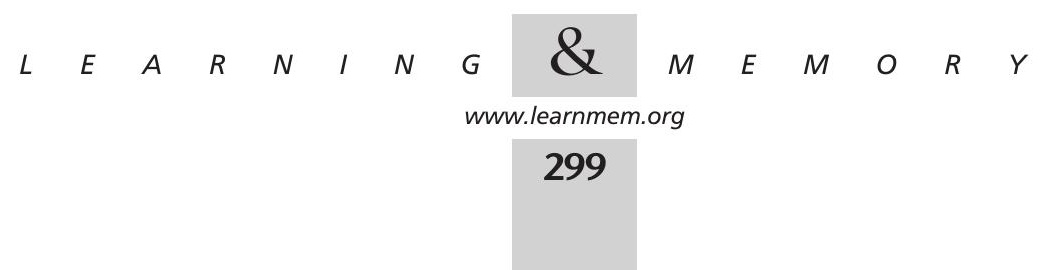


drug history and behavioral results of the rat. In the case of ambiguous placements, the histology was examined by an additional experienced observer who was also blind to the treatment history and behavioral results. The data of those animals whose cannula were misplaced were not included in the statistical analyses. In addition, data from rats whose histology showed evidence of extensive neuronal damage were discarded. The results of the histological analyses indicated that 12 rats had misplaced cannulae (VEHVEH, $n=4$; PHYSO-VEH, $n=7$; PHYSO-MUSC, $n=1$ ) and that the brains of two rats exhibited extensive neuronal damage (PHYSOVEH, $n=1$; PHYSO-MUSC, $n=1$ ).

The spontaneous alternation data were expressed as means and standard errors of the mean (S.E.M.) and analyzed using analysis of variance (ANOVA) and Bonferroni post hoc tests. An $\alpha$ level of 0.05 was used as the criterion of statistical significance.

\section{Experiment 2}

The procedure used in this experiment was the same as that used in experiment 1 with the following exceptions:

Stereotaxic surgical procedures were used to implant one guide cannula aimed at the medial septum and one aimed at the entorhinal cortex (-7.5 mm AP, $6.2 \mathrm{~mm} \mathrm{DV}, 5.3 \mathrm{~mm} \mathrm{ML})$. The unilateral entorhinal cortex cannulae were counterbalanced for hemisphere.

The rats were given an infusion of vehicle or physostigmine $(7.5 \mu \mathrm{g} / \mu \mathrm{L}$ per $\mathrm{min})$ into the entorhinal cannula immediately followed by an infusion of vehicle or muscimol $(114 \mathrm{ng} / 0.5 \mu \mathrm{L}$ for 1 $\mathrm{min}$ ) into the septal cannula. The physostigmine dose was selected on the basis of the results of pilot experiments.

The results of the histological analysis indicated that five rats had misplaced cannulae (VEH-VEH, $n=2$; PHYSO-MUSC, $n=3$ ) and that the brain of one rat (PHYSO-VEH) exhibited extensive neuronal damage. The behavioral results of 14 rats were excluded from the statistical analyses because of insufficient arm entries (i.e., $<10$ arms; VEH-MUSC, $n=7$; PHYSO-MUSC, $n=7$ ).

\section{Experiment 3}

The procedure used in this experiment was the same as that used in experiment 2 with the following exceptions:

Rats were given an infusion of vehicle or physostigmine $(1.875 \mu \mathrm{g} / 0.25 \mu \mathrm{L}$ for $1 \mathrm{~min})$ into the entorhinal cannula immediately followed by an infusion of vehicle or muscimol $(114 \mathrm{ng} / 0.5 \mu \mathrm{L}$ per min) into the septal cannula.

The results of the histological analysis indicated that 10 rats had misplaced cannulae (VEH-VEH, $n=2$; PHYSO-VEH, $n=1$; VEHMUSC, $n=4$; PHYSO-MUSC, $n=3$ ) and that the brains of four rats exhibited extensive neuronal damage (VEH-MUSC, $n=2$; PHYSOMUSC, $n=2$ ). The behavioral results of 15 rats were excluded from the statistical analyses because of insufficient arm entries (i.e., $<10$ arms; VEH-MUSC, $n=8$; PHYSO-MUSC, $n=7$ ).

\section{ACKNOWLEDGMENTS}

This work was supported by MRC G11821018 and NSERC OGP019453. We thank Drs. Benjamin Philpot, Dallas Treit, and Doug Wong-Wylie for their comments on earlier versions of the manuscript as well as Justin Park, Hugo Lehmann, Shauna Kashluba, and Treena Blake for their invaluable technical assistance.

The publication costs of this article were defrayed in part by payment of page charges. This article must therefore be hereby marked "advertisement" in accordance with 18 USC section 1734 solely to indicate this fact.

\section{REFERENCES}

Aggleton, J.P., Keith, A.B., Rawlins, J.N.P., and Sahgal, A. 1992. Removal of the hippocampus and transection of the fornix produce comparable deficits on delayed non-matching to position by rats. Behav. Brain Res. 52: 61-71.

Alonso, A. and Köhler, C. 1984. A study of the reciprocal connections between the septum and the entorhinal area using anterograde and retrograde axonal transport methods in the rat brain. J. Comp. Neurol. 225: 327-343.

Amaral, D.G., Insausti, R., and Cowan, W.M. 1984. The commissural connections of the monkey hippocampal formation. J. Comp. Neurol. 224: 307-336

Ammassari-Teule, M. and Maho, C. 1992. Choice behavior of fornix-damaged rats in radial maze error-free situations and subsequent learning. Physiol. Behav. 51: 563-567.

Bannon, A.W., Curzon, P., Gunther, K.L., and Decker, M.W. 1996. Effects of intra-septal injection of 192-IgG-saporin in mature and aged Long-Evans rats. Brain Res. 718: 25-36.

Baxter, M.G., Bucci, D.J., Gorman, L.K., Wiley, R.G., and Gallagher, M. 1995. Selective immunotoxic lesions of basal forebrain cholinergic cells: Effects on learning and memory in rats. Behav. Neurosci. 109: 714-722.

Beninger, R.J., Jhamandas, K., Boegman, R., and El-Defrawy, S.R. 1986. Effects of scopolamine and unilateral lesions of the basal forebrain on $\mathrm{t}$-maze spatial discrimination and alternation in rats. Pharmacol. Biochem. Behav. 24: 1353-1360.

Berger-Sweeney, J., Heckers, S., Mesulam, M.M., Wiley, R.G., Lappi, D.A., and Sharma, M. 1994. Differential effects on spatial navigation of immunotoxin-induced cholinergic lesions of the medial septal area and nucleus basalis magnocellularis. J. Neurosci. 14: 4507-4519.

Bland, B.H. 1986. The physiology and pharmacology of hippocampal formation theta rhythms. Prog. Neurobiol. 26: 1-54.

Bolhuis, J.J., Strijkstra, A.M., and Kramers, R.J. 1988. Effects of scopolamine on performance of rats in a delayed-response radial maze task. Physiol. Behav. 43: 403-409.

Brioni, J.D., Decker, M.W., Gamboa, L.P., Izquierdo, I., and McGaugh, J.L. 1990. Muscimol injections in the medial septum impair spatial learning. Brain Res. 522: 227-234

Christesen, H.B.T. and Sorensen, K.E. 1989. The topographical and laminar organization of a commissural-associational entorhino-entorhinal projection in the guinea pig. Brain Res. 505: 75-82.

Chrobak, J.J. and Napier, T.C. 1992. Antagonism of GABAergic transmission within the septum disrupts working/episodic memory in the rat. Neuroscience 47: 833-841.

Chrobak, J.J., Stackman, R.W., and Walsh, T.J. 1989. Intra-septal administration of muscimol produces dose-dependent memory impairments in the rat. Behav. Neural Biol. 52: 357-369.

Cooper, J.D. and Sofroniew, M.V. 1996. Increased vulnerability of septal cholinergic neurons to partial loss of target neurons in aged rats. Neuroscience 75: 29-35.

Costa, E., Panula, P., Thompson, H.K., and Cheney, D.L. 1983. The transsynaptic regulation of the septal-hippocampal cholinergic neurons. Life Sci. 32: 165-179.

Dalrymple-Alford, J.C. 1994. Behavioral effects of basal forebrain grafts after dorsal septo-hippocampal pathway lesions. Brain Res. 661: $243-258$

Dember, W.N. 1989. Spontaneous alternation behavior. Springer-Verlag, New York.

Demeter, S., Rosene, D.L., and Van Hoesen, G.W. 1985. Interhemispheric pathways of the hippocampal formation, presubiculum, and entorhinal and posterior parahippocampal cortices in the rhesus monkey: The structure and organization of the hippocampal commissures. J. Comp. Neurol. 233: 30-47.

Dickinson-Anson, H., Aubert, I., Gage, F.H., and Fisher, L.J. 1998. Hippocampal grafts of acetylcholine producing cells are sufficient to

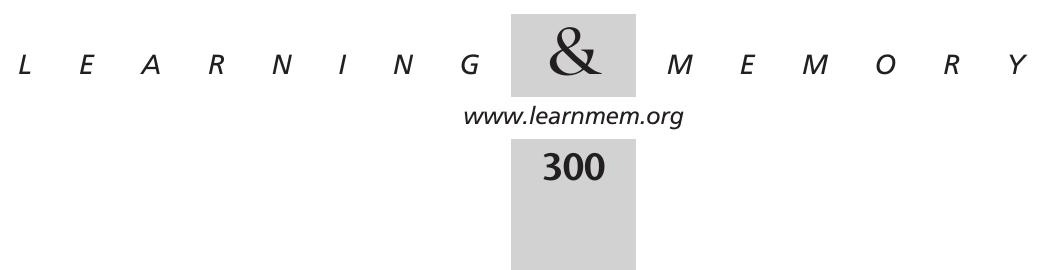


improve behavioral performance following unilateral fimbria-fornix lesions. Neuroscience 84: 771-781.

Dornan, W.A., McCampbell, A.R., Tinkler, G.P., Hickman, L.J., Bannon, A.W., Decker, M.W., and Gunther, K.L. 1996. Comparison of site-specific injections into the basal forebrain on water maze and radial arm maze performance in the male rat after immunolesioning with IgG saporin. Behav. Brain Res. 82: 93-101.

Dunnett, S.B., Low, W.C., Iversen, S.D., Stenevi, U., and Björklund, A. 1982. Septal transplants restore maze learning in rats with fimbria-fornix lesions. Brain Res. 252: 335-348.

Durkin, T. 1992. GABAergic mediation of indirect transsynaptic control over basal and spatial memory testing-induced activation of septo-hippocampal cholinergic activity in mice. Behav. Brain Res. 50: 155-165.

Dutar, P., Bassant, M.H., Senut, M.C., and Lamour, Y. 1995. The septo-hippocampal pathway: Structure and function of a central cholinergic system. Physiol. Rev. 75: 393-427.

Erb, C., Klein, J., Koppen, A., Loffelholz, K., Jeltsch, H., and Cassel, J.C. 1997. Modulation of hippocampal acetylcholine release after fimbria-fornix lesions and septal transplantation in rats. Neurosci. Lett. 231: 5-8.

Fernandes de Lima, V.M., Pijn, J.P., Nunes Filipe, C., and Lopes da Silva, F. 1990. The role of hippocampal commissures in the interhemispheric transfer of epileptiform afterdischarges in the rat: A study using linear and non-linear regression analysis. Electroencephalogr. Clin. Neurophysiol. 76: 520-539.

Fibiger, H.C., Damsma, G., and Day, J.C. 1991. Behavioral pharmacology and biochemistry of central cholinergic neurotransmission. Adv. Exp. Med. Biol. 295: 399-414.

Freund, T.F. and Antal, M. 1988. GABA-containing neurons in the septum control inhibitory interneurons in the hippocampus. Nature 336: $170-173$

Galey, D., Toumane, A., Durkin, T., and Jaffard, R. 1989. In vivo modulation of septo-hippocampal cholinergic activity in mice: Relationships with spatial reference and working memory performance. Behav. Brain Res. 32: 163-172.

Gao, B., Hornung, J.P., and Fritschy, J.M. 1995. Identification of distinct GABA-A receptor subtypes in cholinergic and parvalbumin-positive neurons of the rat and marmoset medial septum diagonal band complex. Neuroscience 65: 101-117.

Gauthier, M. and Destrade, C. 1984. Late post-learning effect of entorhinal cortex electrical stimulation persists despite destruction of the perforant path. Brain Res. 17: 174-179

Gibson, G.E. and Blass, J.P. 1976. Impaired synthesis of acetylcholine in brain accompanying mild hypoxia and hypoglycemia. J. Neurochem. 27: $37-42$.

Gibson, G.E., Blass, J.P., and Jenden, D.J. 1978. Measurement of acetylcholine turnover with glucose used as a precursor: Evidence for compartmentation of glucose in the brain. J. Neurochem. 30: 71-76.

Givens, B. 1995. Low doses of ethanol impair spatial working memory and reduce hippocampal theta activity. Alcohol Clin. Exp. Res. 19: $763-767$

Givens, B.S. and Olton, D.S. 1990. Cholinergic and GABAergic modulation of medial septal area: Effect on working memory. Behav. Neurosci. 104: 849-855

Givens, B.S. and Olton, D.S. 1994. Local modulation of basal forebrain: Effects on working memory and reference memory. J. Neurosci. 14: 3578-3587.

Gloor, P., Salanova, V., Olivier A., and Quesney, L.F. 1993. The human dorsal hippocampal commissure: An anatomically identifiable and functional pathway. Brain 116: 1249-1273.

Gorman, L.K., Pang, K., Frick, K.M., Givens, B., and Olton, D.S. 1994. Acetylcholine release in the hippocampus: Effects of cholinergic and GABAergic compounds in the medial septal area. Neurosci. Lett. 166: 199-202.

Henderson, Z. 1995. Expression of $\mathrm{GABA}_{\mathrm{A}}$ receptor subunit messenger RNA in non-cholinergic neurons of the rat basal forebrain. Neuroscience 65: 1077-1086.
Hepler, D.J., Olton, D.S., Wenk, G.L., and Coyle, J.T. 1985. Lesions in nucleus basalis magnocellularis and medial septal area of rats produce qualitatively similar memory impairments. J. Neurosci. 5: 866-873.

Iijama, T., Witter, M.P., Ichikawa, M., Tominaga, T., Kajiwara, R., and Matsumoto, G. 1996. Entorhinal-hippocampal interactions revealed by real-time imaging. Science 24: 1176-1179.

Imperato, A., Dazzi, L., Obinu, M.C., Gessa, G.L., and Biggio, G. 1993. Inhibition of hippocampal acetylcholine release by benzodiazepines: Antagonism by flumazenil. Eur. J. Pharmacol. 238: 135-137.

Imperato, A., Dazzi, L., Obinu, M.C., Gessa, G.L., and Biggio, G. 1994. The benzodiazepine receptor antagonist flumazenil increases acetylcholine release in the rat hippocampus. Brain Res. 647: 167-171.

Izquierdo, I., Bianchin, M., Silva, M.B., Zanatta, M.S., Walz, R., Ruschel, A.C., Da Silva, R.C., Paczko, N., and Medina, J.H. 1993. CNQX infused into rat hippocampus or amygdala disrupts the expression of memory of two different tasks. Behav. Neural Biol. 59: 1-4.

Izquierdo, I. and Medina, J.H. 1995. Correlation between the pharmacology of long-term potentiation and the pharmacology of memory. Neurobiol. Learn. Mem. 63: 19-32.

Jakab, R.L. and Leranth C. 1995. Septum. In The rat nervous system, (G.I. Paxinus, ed.) Academic Press, San Diego, CA. pp. 405-442.

Jarrard, L.E., Okaichi, H., Steward, O., and Goldschmidt, R.B. 1984. On the role of hippocampal connections in the performance of place and cue tasks: Comparisons with damage to hippocampus. Behav. Neurosci. 98: 946-954.

Jones, R.S.G. 1993. Entorhinal-hippocampal connections: A speculative view of their function. Trends Neurosci. 16: 58-64.

Kelsey, J.E. and Vargas, H. 1993. Medial septal lesions disrupt spatial, but not nonspatial working memory in rats. Behav. Neurosci. 4: 565-574

Kimonides, V.G., Khatibi, N.H., Svendsen, C.N., Sofroniew, M.V., and Hebert, J. 1998. Dehydroepiandrosterone (DHEA) and DHEA-sulfate (DHEAS) protect hippocampal neurons against excitatory amino-acid induced neurotoxicity. Proc. Natl. Acad. Sci. 95: 1852-1857.

Kiss, J., Patel, A.J., Baimbridge, K.G., and Freund, T.F. 1990. Topographical localization of neurons containing parvalbumin and choline acetyltransferase in the medial septum-diagonal band region of the rat. Neuroscience 36: 61-72.

Levey, A.I., Edmunds, S.M., Hersch, S.M., Wiley, R.G., and Heilman, C.J. 1995. Light and electron microscopic study of m2 muscarinic acetylcholine receptor in the basal forebrain of the rat. J. Comp. Neurol. 351: 339-356.

Livesay, P.J., Livesay, D.J., and Syme, G.J. 1981. Spontaneous alternation in the white rat: A learning and memory phenomenon. Behav. Neural Biol. 32: 158-169.

Marighetto, A., Durkin, T., Toumane, A., Lebrun, C., and Jaffard, R. 1989. Septal alpha-noradrenergic antagonism in vivo blocks the testing-induced activation of septo-hippocampal cholinergic neurones and produces a concomitant deficit in working memory performance of mice. Pharmacol. Biochem. Behav. 34: 553-558.

Markowska, A.L., Givens, B., and Olton, D.S. 1990. Cholinergic activation of medial septal area can restore working memory in old rats and in scopolamine-treated young rats. Soc. Neurosci. Abstr. 16: 918 .

Markowska, A.L., Olton, D.S., and Givens, B. 1995. Cholinergic manipulations in the medial septal area: Age-related effects on working memory and hippocampal electrophysiology. J. Neurosci. 15: 2063-2073.

Markram, H. and Segal, M. 1990. Acetylcholine potentiates responses to $N$-methyl-D-aspartate in the rat hippocampus. Neurosci. Lett. 18: 62-65.

Matsuoka, N. and Aigner, T.G. 1996. Cholinergic-glutamatergic interactions in visual recognition memory of rhesus monkeys. Neuroreport 7: 565-568.

McNamara, R.K. and Skelton, R.W. 1995. Effects of intracranial infusions of chlordiazepoxide on spatial learning in the Morris water maze. II. Neuropharmacological specificity. Behav. Brain Res. 59: 193-204.

M'Harzi, M. and Jarrard, L.E. 1992. Strategy selection in a task with spatial and nonspatial components: Effects of fimbria-fornix lesions in rats. Behav. Neural Biol. 58: 171-179.

Micheau, J., Messier, C., and Jaffard, R. 1995. Glucose enhancement of

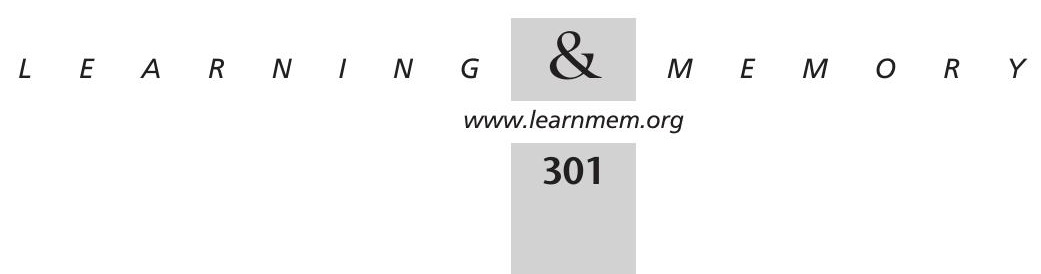


scopolamine-induced increase of hippocampal high-affinity choline uptake in mice: Relation to plasma glucose levels. Brain Res. 685: 99-104

Milner, T.A., Loy, R., and Amaral, D.G. 1983. An anatomical study of the development of the septo-hippocampal projection in the rat. Dev. Brain Res. 8: 343-371.

Mitchell, S.J., Rawlins, J.N.P., Steward, O., and Olton, D.S. 1982. Medial septal area lesions disrupt theta rhythm and cholinergic staining in medial entorhinal cortex and produce impaired radial arm maze behavior in rats. J. Neurosci. 2: 292-302.

Moor, E., Auth, F., DeBoer, P., and Westerink, B.H.C. 1996. Septal and hippocampal glutamate receptors modulate the output of acetylcholine in hippocampus: A microdialysis study. J. Neurochem. 67: 310-316

Moor, E., DeBoer, P., and Westerink, B.H.C. 1998. GABA receptors and benzodiazepine binding sites modulate hippocampal acetylcholine release in vivo. Eur. J. Pharmacol. 359: 119-126.

Nagahara, A.H. and McGaugh, J.L. 1992. Muscimol infused into the medial septum area impairs long term memory but not short term memory in inhibitory avoidance, water maze place learning and rewarded alternation tasks. Brain Res. 591: 54-61.

Nagahara, A.H., Brioni, J.D., and McGaugh, J.L. 1992. Effects of intra-septal infusion of muscimol on inhibitory avoidance and spatial learning: Differential effects of pretraining and posttraining administration. Psychobiology 20: 198-204.

Naumann, T., Linke, R., and Frotscher, M. 1992. Fine structure of rat septo-hippocampal neurons. I. Identification of septo-hippocampal projection neurons by retrograde tracing combined with electron microscopic immunocytochemistry and intracellular staining. J. Comp. Neurol. 325: 207-218

Nilsson, O.G. and Björklund, A. 1992. Behavior dependent changes in acetylcholine release in normal and graft-reinnervated hippocampus: Evidence for host regulation of grafted cholinergic neurons. Neuroscience 49: 33-44

Nilsson, O.G., Shapiro, M.L., Gage, F.H., Olton, D.S., and Björklund, A. 1987. Spatial learning and memory following fimbria fornix transection and grafting of fetal septal neurons to the hippocampus. Exp. Brain Res. 67: 195-215.

Nilsson, O.G., Kalen, P., Rosengren, E., and Björklund, A. 1990. Acetylcholine release in the rat hippocampus as studied by microdialysis is dependent on axonal impulse flow and increases during behavioral activation. Neuroscience. 36: 325-338.

Ohno, M. and Watanabe, S. 1996. Interactive processing between glutamatergic and cholinergic systems involved in inhibitory avoidance learning of rats. Eur. J. Pharmacol. 26: 145-147.

Packard, M.G. and Teather, L.A. 1998. Amygdala modulation of multiple memory systems: Hippocampus and caudate-putamen. Neurobiol. Learn. Mem. 69: 163-203.

Packard, M.G., Cahill, L., and McGaugh, J.L. 1994. Amygdala modulation of hippocampal-dependent and caudate nucleus-dependent memory processes. Proc. Natl. Acad. Sci. 91: 8477-8481.

Packard, M.G., Kohlmaier, J.R., and Alexander, G.M. 1996. Posttraining intrahippocampal estradiol injections enhance spatial memory in male rats: Interaction with cholinergic systems. Behav. Neurosci. 110: 626-632

Pang, K.C.H. and Nocera, R. 1998. Interactions between 192-IgG saporin and intraseptal cholinergic and GABAergic drugs: Evidence for a role of cholinergic medial septal neurons in spatial working memory. Behav. Neurosci. 113: 265-275.

Parent, M.B. and Gold, P.E. 1997. Intra-septal infusions of glucose potentiate inhibitory avoidance deficits when co-infused with the GABA agonist muscimol. Brain Res. 745: 317-320.

Parent, M.B., Laurey, P.T., Wilkniss, S., and Gold, P.E. 1997. Intra-septal infusions of muscimol impair spontaneous alternation performance: Infusions of glucose into the hippocampus, but not the medial septum, reverse the deficit. Neurobiol. Learn. Mem. 68: 75-85.

Paxinos, G. and Watson, C. 1986. The rat brain in stereotaxic coordinates. Academic Press, New York.
Ragozzino, M.E., Unick, K.E., and Gold, P.E. 1996. Hippocampal acetylcholine release during memory testing in rats: Augmentation by glucose. Proc. Natl. Acad. Sci. 93: 4693-4698.

Ragozzino, M.E., Pal, S.N., Unick, K., Stefani, M.R., and Gold, P. 1998. Modulation of hippocampal acetylcholine release and spontaneous alternation scores by intra-hippocampal glucose injections. J. Neurosci. 18: $1595-1601$.

Richman, C.L., Dember, W.N., and Kim, P. 1987. Spontaneous alternation behavior: A review. Curr. Psychol. Res. Rev. 5: 358-391.

Roozendaal, B., Nguyen, B.T., Power, A.E., and McGaugh, J.L. 1999. Basolateral amygdala noradrenergic influence enables enhancement of memory consolidation induced by hippocampal glucocorticoid receptor activation. Proc. Natl. Acad. Sci. 96: 11642-11647.

Secor, A., Nocera, R., and Pang, K.C.H. 1999. GABAergic septohippocampal neurons are not necessary for spatial memory. Soc. Neurosci. Abstr. 25: 1388.

Shannon, H.E., Bemis, K.G., and Hart, J.C. 1990. Assessment of working memory in rats using spatial alternation behavior with variable retention intervals: Effects of fixed ratio size and scopolamine. Psychopharmacology 100: 491-497.

Srebro, B., Harkmark, W., and Köhler. 1979. Afferent and efferent projections of the entorhinal cortex in the rat. Neurosci. Lett. Suppl. 3: 143 .

Stackman, R.W. and Walsh, T.J. 1995. Anatomical specificity and time dependence of chlordiazepoxide-induced spatial memory impairments. Behav. Neurosci. 109: 436-445.

Staubli, U., Perez, Y., Xu, F.B., Rogers, G., Ingvar, M., Stone-Elander, S., and Lynch, G. 1994. Centrally active modulators of glutamate receptors facilitate the induction of long-term potentiation in vivo. Proc. Natl. Acad. Sci. 8: 11158-11162.

Stone, W.S., Cottrill, K.L., Walker, D.L., and Gold, P.E. 1988. Blood glucose and brain function: Interactions with CNS cholinergic systems. Behav. Neural Biol. 50: 325-334.

Toth, K., Freund, T.F., and Miles, R. 1997. Disinhibition of rat hippocampal pyramidal cells by GABAergic afferents from the septum. J. Physiol. 500: 463-474.

Van der Zee, E.A. and Luiten, P.G.M. 1994. Cholinergic and GABAergic neurons in the rat medial septum express muscarinic acetylcholine receptors. Brain Res. 652: 263-272.

Wainer, B. H., Levey, A.I., Rye, D.B., Mesulam, M.M., and Mufson, E.J. 1985. Cholinergic and noncholinergic septo-hippocampal pathways Neurosci. Lett. 54: 45-52.

Walsh, T.J., Stackman, R.W., Emerich, D.F., and Taylor, L.A. 1993. Intra-septal injection of GABA and benzodiazepine receptor ligands alters high-affinity choline transport in the hippocampus. Brain Res Bull. 31: 267-271

Walsh, T.J., Herzog, C.D., Gandhi, C., Stackman, R.W., and Wiley, R.G. 1996. Injection of IgG 192-saporin into the medial septum produces cholinergic hypofunction and dose dependent working memory deficits. Brain Res. 726: 69-79.

Wan, R., Givens, B.S., and Olton, D.S. 1995. Opioid modulation of working memory: Intra-septal, but not intraamygdaloid, infusions of B-endorphin impair performance in spatial alternation. Neurobiol. Learn. Mem. 63: 74-86.

Wood, P.L. 1986. Pharmacological evaluation of GABAergic inputs to the nucleus basalis-cortical and the septal-hippocampal cholinergic projections. Can. J. Physiol. Pharmacol. 64: 325-328.

Wu, M., Shanabrough, M., Leranth, C., and Alreja, M. 2000. Cholinergic excitation of septohippocampal GABA but not cholinergic neurons: Implications for learning and memory. J. Neurosci. 20: 3900-3908.

Wyss, J.M., Swanson, L.W., and Cowan, M.W. 1979. A study of subcortical afferents to the hippocampal formation in the rat. Neuroscience 4: $463-477$.

Received March 20, 2000; accepted in revised form August 9, 2000.

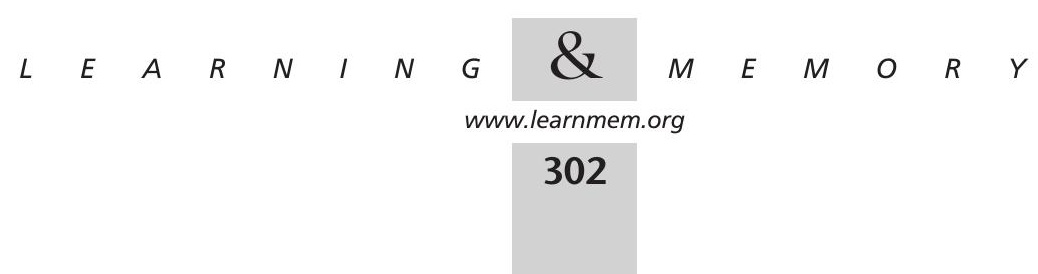




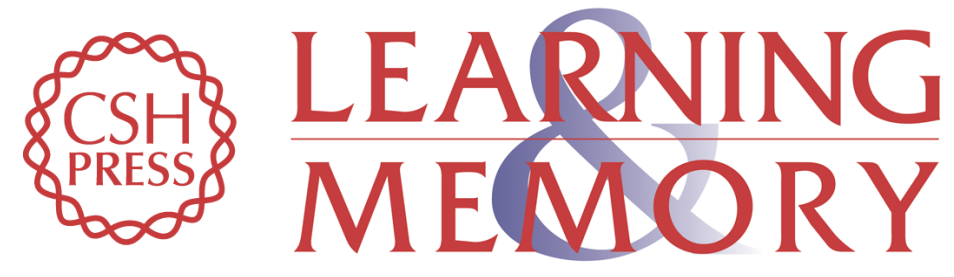

\section{Increasing Acetylcholine Levels in the Hippocampus or Entorhinal Cortex Reverses the Impairing Effects of Septal GABA Receptor Activation on Spontaneous Alternation}

Aldemar Degroot and Marise B. Parent

Learn. Mem. 2000, 7:

Access the most recent version at doi:10.1101//m.32200

References This article cites 89 articles, 11 of which can be accessed free at:

http://learnmem.cshlp.org/content/7/5/293.full.html\#ref-list-1

License

Email Alerting Receive free email alerts when new articles cite this article - sign up in the box at the Service top right corner of the article or click here. 